\title{
A critical realist inquiry in conducting interdisciplinary research: an analysis of LUCID examples
}

\author{
Marvam Nastar $^{1}, \underline{\text { Chad S. Boda }}^{1}$ and Lennart Olsson ${ }^{1}$
}

\begin{abstract}
In recent years, a strong natural science hegemony has predominantly framed our understanding of sustainability challenges and, as a result, the production of solution strategies. In countering this, some academic centers have sought to promote interdisciplinary research, starting from the recognition that the scale and complexity of sustainability challenges necessitates a plurality of different social science perspectives to be incorporated in research. In this article, we analyze the process and outcomes of one of these centers, namely, the Lund University Centre of Excellence for Integration of the Social and Natural Dimensions of Sustainability (LUCID), maintaining a heavy emphasis on incorporating social sciences into interdisciplinary sustainability research from its inception. First, we identify and motivate the selection of a consistent set of criteria for evaluating interdisciplinary research processes and outcomes. Second, we apply these criteria in an analysis of a selection of scholarly work produced at LUCID. Third, we evaluate the impacts of LUCID's institutional settings on the process of interdisciplinary research. Finally, we assess to what degree the outcomes of LUCID research have managed to produce the synthetic integrated knowledge required to analyze and address complex sustainability challenges. Although the LUCID work in aggregate represents a plurality of social science perspectives, our analysis suggests that a meaningful synthetic integration of knowledge was accomplished in cases where researchers employed retroductive logic and adhered to the principles of methodological pluralism. In highlighting the need to systematically incorporate these essential elements into the research process, we stress the importance of institutional settings in terms of finance, administration, and providing a conducive intellectual environment wherein authentic interdisciplinarity can emerge. Maintaining the kinds of horizontal and vertical institutional integration characteristic of such conducive settings, however, poses a major challenge in light of current trends, at least in Sweden, toward more compartmentalized, disciplinary university structures.
\end{abstract}

Key Words: antireductionism; critical realism; interdisciplinary research centers; methodological pluralism; retroduction; sustainability science

\section{INTRODUCTION}

In recent years, a growing number of natural scientists interested in the interaction between nature and society have been awarded prestigious prizes for their research on global sustainability issues ${ }^{[1]}$. To date, no social scientist has come close to such a level of recognition. There seems to be a strong hegemony of natural sciences framing and shaping our understanding of the dynamics of Earth biophysical systems and society at the global level. For example, the influential and highly cited book by Steffen et al. (2006) makes implicit links between a wide range of biogeophysical changes and trends in a random set of social variables, such as GDP, human population, number of motor vehicles, and number of McDonald restaurants worldwide, while being silent about the political economy at play. Another illustrative example is Schellnhuber's "planetary machinery" from 1999, in which the Earth system is seen as an enormous machine where subsystems interact through numerous feed-back mechanisms, but where society is reduced to a circle called "human activity" (Schellnhuber 1999). Strong hegemonic influence of natural science over the scientific conceptualization of sustainability issues is troublesome, not least because we may confuse or conflate the dynamics of change ascribed to the nonhuman world with those of the social world, by, for example, concealing the uneven power relations inherent in societies (and absent from ecologies) that are crucial for understanding social action and change processes (Olsson et al. 2015). Such confusion can in turn facilitate the production of solution strategies that are not reflective of best scientific knowledge and practice, in particular solution strategies that lack a basis in appropriate social theories (O'Byrne et al. 2018).
Characterized by open-systems complexity, real-world sustainability challenges often contain emergent properties and are determined by a multiplicity of mechanisms, all characteristics that necessitate genuinely synthetic interdisciplinarity in research (Bhaskar et al. 2010). This involves the epistemic integration of the knowledge of (changing and emerging) mechanisms in both the natural and social world, which in turn requires developing new concepts, theories, and modes of understandings; furthermore, the capacity to effectively produce such synthetic concepts, theories, and models requires conducive institutional settings (Bhaskar et al. 2010). The effective integration of social scientific knowledge in this process is particularly crucial but seriously underrepresented and asymmetrical (Viseu 2015). Faced with these inadequacies, rather than being an "outdated" issue, it is more important than ever that we assess the way interdisciplinarity has been carried out in order to evaluate to what extent interdisciplinary efforts have been able to achieve the goal of synthetic scientific knowledge production, and what factors inhibit or facilitate this goal.

In doing so, we look at the process of knowledge production at one of the sustainability research centers explicitly predicated on facilitating interdisciplinarity with a heavy emphasis on social science, namely, the Lund University Centre of Excellence for Integration of the Social and Natural Dimensions of Sustainability (LUCID). LUCID received the Linnaeus grant in 2008, sponsored by the Swedish Research Council. Linnaeus grants are distributed directly to the selected research fields (instead of centrally to the higher education institutions) to promote structural changes in order to support new collaborations across scientific fields. LUCID is one of the early 
endeavors at the $\mathrm{PhD}$ level, and as such sought to bring together scholars across different disciplines under one unique consortium of academic departments to work jointly on theory, methodology, and education for sustainability (LUCID Science Plan 2008). In evaluating the LUCID research process, we focus explicitly on scientific knowledge production as opposed to more so-called "open knowledge systems" (Cornell et al. 2013). This deliberate decision is based on our recognition of the need for a strengthening of the theoretical foundation of interdisciplinary collaboration across ontological divides. In this context, however, we of course see the need for harnessing both scientific knowledge and knowledge acquired through practical experience (Persson, Johansson, and Olsson, unpublished manuscript).

In this paper, we aim (1) to identify a consistent set of criteria for conducting and evaluating interdisciplinary research, (2) to analyze the process of interdisciplinary research conducted at the LUCID research school over the previous decade based on these criteria, (3) to evaluate the institutional settings and arrangements associated with LUCID in terms of their impacts on the process of interdisciplinary research, and (4) to assess to what degree the outcomes of LUCID research have managed to produce satisfactory interdisciplinary explanations of sustainability challenges.

\section{ANALYZING INTERDISCIPLINARITY: A CRITICAL REALIST APPROACH}

Ideas about what interdisciplinarity is and how it is best conducted differ. Because of this, the analysis and evaluation of any research program in terms of interdisciplinarity would be aided by the adoption and application of a consistent set of criteria. In this paper we draw on the theory of interdisciplinarity derived from the philosophy of science broadly known as critical realism (CR), most prominently developed by Roy Bhaskar.

The perspective of transcendental (later, critical) realism was developed out of Bhaskar's dual critique of empirical realism and transcendental idealism from which he sought to demonstrate that neither of these philosophical perspectives could maintain adequate explanations of the possibility of scientific, in particular experimental, activity (Bhaskar 2013). From this critique, Bhaskar developed a philosophy of science grounded in a realist ontology, a relativist epistemology, and an appeal to judgmental rationality, which he later collectively referred to as the "holy trinity" of critical realism (Bhaskar et al. 2010:1). Bhaskar's realism is articulated in terms of a stratified ontology that is based on distinguishing between (1) the empirical domain that contains our observations and experiences of an issue, (2) the actual domain that centers on the mechanisms causing those empirical experiences, and (3) the real domain that revolves around the enduring structures that cause actual and empirical events, which are geographically and historically shaped (Archer and Bhaskar 1998, Sayer 2000).

Epistemologically, Bhaskar emphasizes the need to avoid the "epistemic fallacy" (Bhaskar et al. 2010), meaning the tendency to conflate being (ontology) with the knowledge of being (epistemology). Instead, CR distinguishes between two dimensions of knowledge, (1) the intransitive dimension, which involves the relatively unchanging objects of scientific investigation located at varying levels of the stratified world and existing independently of our knowledge, and (2) the transitive dimension, which involves the theories and discourses we use to represent objects of the intransitive dimension. This disambiguation of ontology and epistemology has important implications for how we should conceive scientific knowledge in relation to its object of study. As Isaksen (2016:2) notes, because critical realism establishes the world as "absolutely or relatively independent of our enquiries, and we therefore do not get direct or immediate access to the reality we study," all knowledge endeavors are necessarily epistemically relative, meaning the nature of knowledge is such that "there is no way of knowing the world except under particular, more or less historically transient descriptions" (Bhaskar 2009:99). The necessity of epistemic relativity does not, however, preclude the possibility of objective and rational theory choice, and indeed the exercise of judgmental rationality in $\mathrm{CR}$ scientific practice is indispensable though often neglected (Isaksen 2016).

The way interdisciplinarity is conceptualized in CR, and the reasons why it is seen as necessary when researching complex sustainability challenges, are grounded in these ontological, epistemological, and judgmental foundations. For example, because the world is stratified and systemically open, complex phenomena such as climate change will necessarily involve a wide variety of simultaneously acting and interacting determinates operating at different spatial and temporal scales and levels of reality; furthermore, stratification means many empirical outcomes will exhibit emergent properties. Taken together, these implications imply that empirical phenomena are causally nonreducible, a condition that necessitates interdisciplinarity in analysis in order to make conceptual links among this stratified multiplicity of determinates (Bhaskar et al. 2010). In more concrete terms, (Bhaskar et al. 2010:9) has argued that complex, open-system, social-environmental phenomena such as climate change, land-use change, water scarcity, and loss of biodiversity can only be properly understood in terms of what he calls fourplanar social being, the idea that "specifies that every social event occurs in at least four dimensions, that of material transactions with nature; that of social interactions between humans; that of social structure proper; and that of the stratification of the embodied personality." As shown in Figure 1, this four-planar social being is, furthermore, situated at a hierarchy of scalar levels that allows us to "define distinct levels of agency and collectively with which social explanation may be concerned" (Bhaskar et al. 2010:9).

Fig. 1. Ontological stand of dialectical critical realism. Adopted from (Bhaskar et al. 2010).

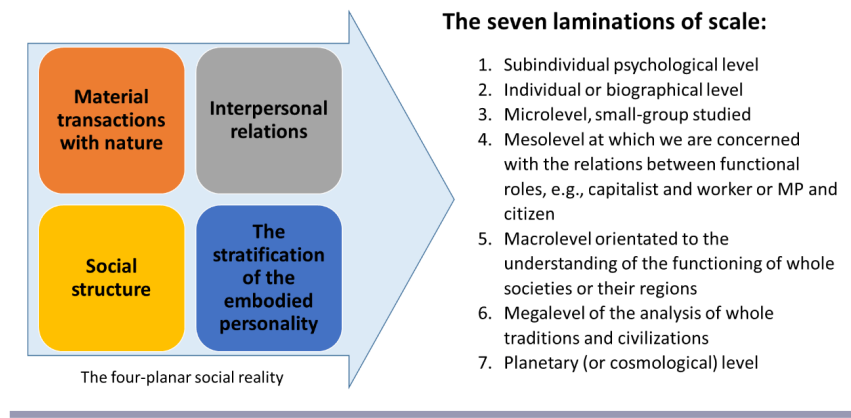


Fig. 2. Process of conducting interdisciplinary knowledge (Bhaskar et al. 2017, reproduced by permission of Tayor \& Francis Books UK).

\section{Ontology (intransitive dimension)}

(disambiguation)

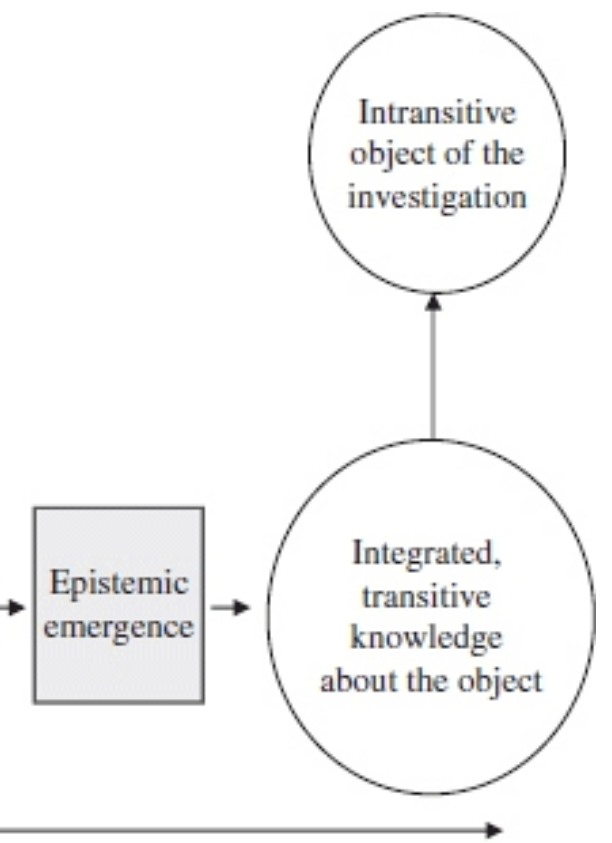

Epistemology (transitive dimension)

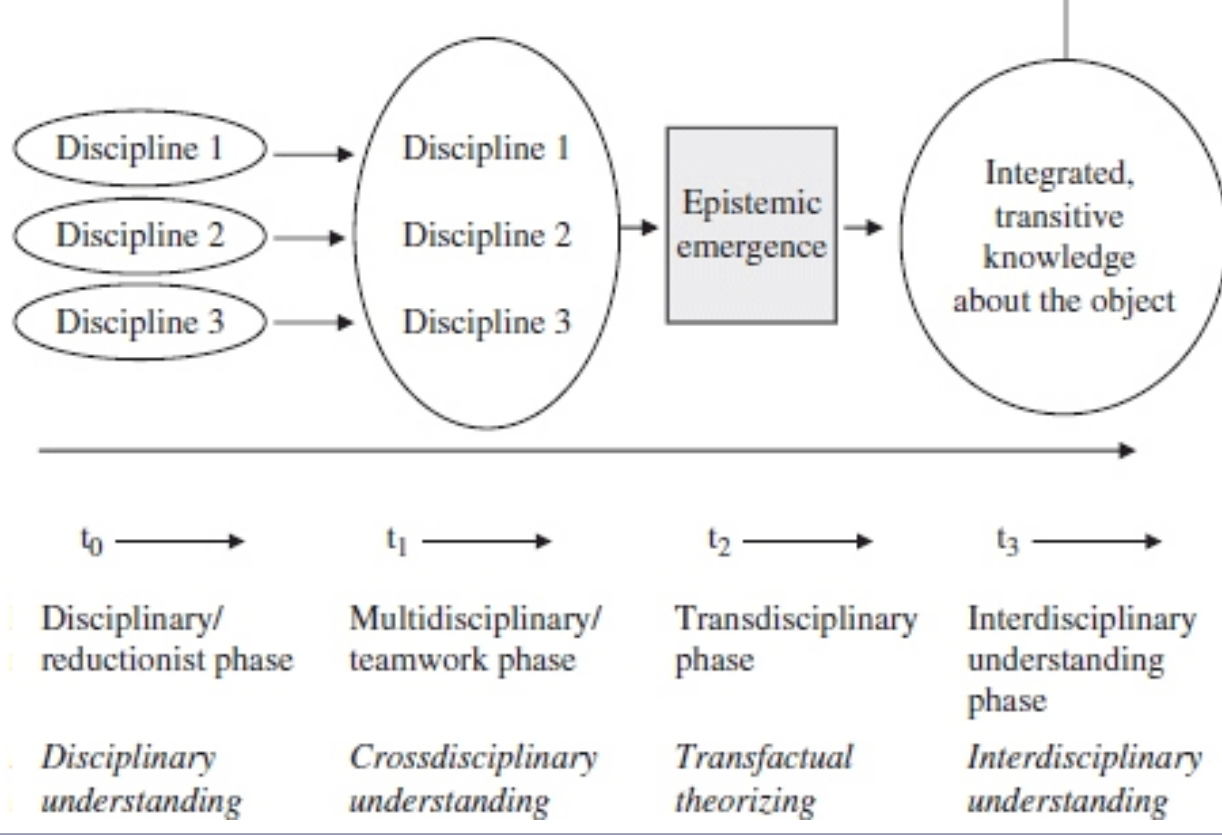

These four dialectically interdependent planes constitute what Bhaskar calls a "laminated system" or "totality," a concept that "pinpoints the meshing of explanatory mechanisms at several different levels of reality and possible orders of scale" (Bhaskar et al. 2010:ix), wherein understanding any level or dimension necessarily involves reference to the other levels or dimensions. There is no a priori account of what levels or the number of levels that may be involved to achieve satisfactory explanations about a phenomenon (Bhaskar et al. 2010). In the field of sustainability science, for example, this means that researchers may refer to different mechanisms at some or all of these levels, depending on the specifics of the concrete problem at hand, in order to investigate a laminated system and come up with satisfactory explanations of sustainability challenges.

Epistemologically and methodologically, a CR perspective implies that progress in interdisciplinary scientific work will necessarily involve the potential creative employment of models, analogies, and insights from a variety of different fields and disciplines other than one's own, drawing on not only interdisciplinary knowledge, but methodological pluralism (Bhaskar et al. 2010). This process follows a procedural logic as outlined in Figure 2.
Bhaskar et al. (2017) posit that integration of knowledge to achieve true interdisciplinarity begins with compartmentalized disciplinary thinking wherein experienced disciplinary researchers pursue their reductionist approach effectively (t0). When researchers recognize the need to incorporate the insights from other disciplines to achieve a full explanation of an event, the process enters the next phase, known as multidisciplinary, involving intentional communication across disciplinary boundaries ( $\mathrm{t} 1$ ). As researchers start to learn from each other about how their varying disciplines can contribute to problem understanding and solution development, the process enters a phase where the possibility of emerging new ideas and theories increases ( $\mathrm{t} 2$ ). This then can lead to the production of integrated transitive knowledge by which one can form more comprehensive conceptualizations of the object of investigation, supporting an interdisciplinary understanding of a given phenomenon (t3).

When it comes to analyzing a concrete research process, by following the movement from one phase to another, one can explore and evaluate if and how understandings of a variety of phenomena and changing and emerging mechanisms in both the natural and social world have been enhanced. In this way, the CR understanding of the interdisciplinary research process provides 
a set of content and procedural criteria by which we can trace the process of knowledge integration. Following this, we can draw conclusions about past research endeavors and identify potentially fruitful ways of progressing research aimed at articulating complex open-systems phenomena such as sustainability challenges.

Summarizing the above ontological, epistemological, and procedural foundations of CR, Bhaskar et al. (2010) delineates the following criteria as necessary for conducting genuine interdisciplinary in research:

1. Disambiguate ontology and epistemology and incorporate antireductionism position

2. Explain the open-systemic phenomena, e.g., climate change, in terms of a laminated totality

3. Emphasize methodological pluralism, in terms of integration of theories and methods

Supportive institutional settings for the following:

1. the dissolution of career, administrative, and financial barriers to interdisciplinary research

2. getting some familiarity with other disciplines

3. giving a sense of a secure, recognized place or home in a single disciplinary tradition while engaging in interdisciplinary research

Following, we evaluate the research conducted at the LUCID research center based on the above criteria, wherein the first three are related to scientific process of knowledge integration, and the last three are used to assess institutional arrangements. Following this, we offer reflections on the significance of each criterion and discuss to what extent these can be made to facilitate successful interdisciplinary research.

\section{CASE STUDY AND DATA COLLECTION METHODS}

\section{The LUCID research school}

Starting from the recognition that many advocates of sustainability science have been strongly grounded in natural sciences, both theoretically and methodologically, a strong emphasis in LUCID research is placed on matters of justice, politics, and power relations to achieve an adequate understanding of nature-society interactions. In particular, LUCID emphasizes the need to scrutinize sustainability strategies and outcomes in terms of intergenerational, international, intersectional dimensions of justice and fairness (LUCID Science Plan 2008).

In undertaking this scientific scrutiny, the LUCID program highlights two cross-cutting approaches to scientific investigation open to individual researchers: problem-solving approaches and critical approaches (LUCID Science Plan 2008). Building on Robert Cox's conceptual distinction of research strategies, the former approach strives to optimize the application of theories to a given problem and to reduce complex problems to a limited number of variables that can be studied within existing theoretical frameworks and institutional settings (Cox 1981). The latter approach, however, questions the basic, constitutive assumptions of theoretical frameworks and the ways they more or less adequately capture the complexity of a given problems, the more general aim being to be more reflective upon the process of theorizing itself (LUCID Science Plan 2008). The joint critical and problem-solving research strategy underpins the need for developing new concepts and theories as well as creative methods for understanding and addressing complex open-systemic phenomena, or in other words, the need for interdisciplinary research.

\section{The core team and scholarly work}

The constellation of centers and departments that made up the LUCID research consortium includes the Lund University Centre for Sustainability Studies (LUCSUS) and the departments of Philosophy, Human Ecology, Human Geography, Physical Geography, and Political Science. Since 2009, LUCID has been the host of more than 100 researchers. This included $\mathrm{PhD}$ graduates, current candidates, and steering committee members as well as guest lecturers, researchers, and organizers of events, i.e., seminars, workshops, courses, conferences, social events, etc., that have been funded fully or partially by LUCID.

Because this investigation is interested specifically in the production of interdisciplinary research, we moved to focus solely on the scholarly work committed to objectives of the program. In doing so, we identified 44 positions, including PhD candidates/ graduates, supervisors, and steering committee members, who were fully or partially funded by LUCID. From this cohort of LUCID researchers, a selection of scholarly work produced by LUCID participants meeting the following criteria was then assembled:

- $\mathrm{PhD}$ candidates who were recruited in relation to the LUCID plan, mentioned in the job application (may be funded by LUCID OR respective centers/departments)

- Graduated from the PhD program OR

- Passed her final seminar and handed in her thesis manuscript where the research aims, methodology, and (partial) contributions are clear in relation to the objectives of the LUCID research plan OR

\section{- Acted as main supervisors of $\mathrm{PhD}$ candidates}

After applying the above selection criteria, 31 researchers were identified as the LUCID core team, of whom 15 were affiliated with LUCSUS (the coordinating center in LUCID) and the rest were distributed almost equally in other centers and departments.

In mapping out the LUCID research activities by the core team, data were collected in three steps. First, a review of each individual piece of work was undertaken to explore to what extent the research aims and analyses were in line with the LUCID aims and objectives. This included the LUCID PhDs' final seminar or thesis manuscripts and a selection of journal articles, book chapters, and research proposals by steering committee members who sent their selected materials and participated in the survey and interviews (29 out of 31). Second, a survey was sent to the authors to understand how the researchers perceive their work and contributions to the program objectives. Unlike the $\mathrm{PhD}$ candidates'/graduates' work, analyzing the senior researchers' work in relation to the LUCID aims was not feasible given the limitations of space in the formats of journal articles or book chapters as well as the diversity of the selected publications in the research topics. To address this, in the third step, several in-depth semiopen interviews were conducted 
with researchers to position their work in reference to the program objectives. The interviews included six members of the LUCID steering committee (one representative from each department/ center) and the coordinator of the LUCID program.

The materials collected from the literature reviews, surveys, and interviews provided the basis for exploring how researchers have attempted to achieve the objectives of the LUCID research plan as well as for further analysis in relation to the CR criteria for genuine interdisciplinarity.

\section{The LUCID examples}

The examples of LUCID research analyzed in this paper cover a diverse range of sustainability challenges including, but not limited to, climate change, land use change, water scarcity, and biodiversity loss. All of these challenges represent complex opensystem phenomena where the need for interdisciplinary knowledge is particularly apparent.

Although many researchers could identify these themes in their work, some also mentioned the scope of their research was not necessarily limited to these preidentified categories, arguing that their work cuts across many or all of these interlinked challenges, or that it expands the boundaries of consideration beyond those suggested in the initial LUCID research plan. For example, in the water field, research has gone beyond the notion of water scarcity as defined in the original LUCID research plan and has been expanded to include issues of water allocation and distribution in and between rural and urban areas while linking them with land use change and climate change issues (Islar 2013, Nastar 2014, Ramasar 2014, Valencia 2016). Also, in one particular case, i.e., Thorén (2015), we could not situate the research in relation to the given four themes because of the theoretical and philosophical nature of the dissertation. In a sense, we thought this work comprises all the categories indirectly but that it did not conform to the initial LUCID sustainability challenge themes.

As mentioned earlier, LUCID highlight the importance of analyzing sustainability challenges and goals based on three dimensions of justice and fairness: the intergenerational, the international, the intersectional. These aspects have been discussed in most of the researchers' work, directly or indirectly.

Formulation of the sustainability goals in terms of justice and fairness brings to the fore the importance of critically reframing sustainability challenges by questioning the dominant underlying assumptions in modern society that inform and direct its interactions with nature (Jerneck et al. 2011). A literature review of the selected LUCID publications as well as insights from the surveys and interviews, show that the primary goal of numerous individual research projects might not have been articulated using these precise terms. However, they were inspired by these notions in setting their research strategies and activities and aimed to address them, though to varying degrees depending on the study. The findings of our review of LUCID publications show that the intergenerational aspect of fairness and justice has been less focused in the LUCID research, with 4 out of $16 \mathrm{PhD}$ researchers explicitly addressing the topic (Brandstedt 2013, Islar 2013, Krause 2013, Boda 2018). Overall, the intersectional and international aspects of sustainability goals were discussed more in the program.

Rethinking the fundamental concepts that capture the interconnections between nature and society is tightly linked with integrated approaches mentioned in LUCID, namely problemsolving approaches and critical approaches.

Most of the LUCID researchers (24 out of 29, surveyed or interviewed) used solely critical thinking research strategy or in combination with problem-solving approaches. A diverse range of theories involved in critical research varied from poststructural, postfunctional, postcolonial, feminist, critical development, Marxist, financialization, and critical urban theories to normative theories, understandings of values, perceptions and beliefs, critical approaches to resilience and agroecology, environmental justice, capability approach to human development, and so forth. Whether such a diverse theoretical content in LUCID amounts to novel theorizing that would lead to truly interdisciplinary knowledge will be discussed below.

\section{A CR ENQUIRY IN CONDUCTING INTERDISCIPLINARY RESEARCH}

Focusing on complex, open-systems phenomena, the LUCID examples have incorporated varying considerations of justice and fairness and drawn on a wide variety of critical and problemsolving theories and methods. All of these characteristics suggest that LUCID research should likewise be interdisciplinary.

\section{Disambiguation of ontology and epistemology and antireductionism}

From a CR's perspective, conducting successful interdisciplinary research requires adopting the basic distinction between the objective world and our understandings of it (Bhaskar et al. 2010). The idea that researchers should avoid the "epistemic fallacy," that is, collapsing together being and the knowledge of being, likewise suggests research should take an antireductionist stance when conceptualizing objects of scientific investigation (Bhaskar et al. 2010). The need for an antireductionist position is furthermore derived from the idea that reality comprises multiple totalities and is in constant movement and change, and, following this, that we should not reduce the complexity of the social world to some subset of biophysical entities (Bhaskar et al. 2010, Creaven 2012).

The LUCID examples demonstrate some achievements in adopting the requirements of disambiguation and antireductionism, though uneven. A review of LUCID PhD theses, for example, showed that the ontological and epistemological positions adopted can broadly be categorized based on three approaches: constructivist, critical realist, and (post)positivist.

Almost half of the theses explicitly invoked critical realism as a philosophical framework to bring different theories together and to analyze the subject of their studies. Although critical realism seemed to be a prevalent methodology in the LUCID graduates' work, understandings and applications of it varied from delineating ongoing debates on ontology and epistemology in length (e.g., Malm 2014, Nastar 2014, Ramasar 2014, Sjöström 2015, Valencia 2016, Warlenius 2017, Boda 2018) to a short introductory paragraph (e.g., Busch 2016). The choice of philosophy of science also had some bearing on the concrete content that was brought into focus in a given research project. The theses that adopted a constructivist approach (e.g., Bettini 2013, Brandstedt 2013, Islar 2013, Andersson 2014, Hansen 2014, Kaijser 2014) tended to also maintain a focus on issues of, for instance, intersectionality and discourses around the topic of the 
study. The research relying on a (post)positivist approach (e.g., Yengoh 2013, Busch 2016; E. Johansson, unpublishedmanuscript), however, tended to be more engaged with different techniques of data collection and empirical materials than engagement with theoretical debates on the subject.

In some cases, however, the correspondence between the stated philosophical position and the actual work conducted was more ambiguous, for example, if a researcher claimed to be utilizing CR while the research methodology actually employed suggested positivism. The apparent disparity between the claimed ontological and epistemological stance adopted by some researchers and the actual methodological approach (both in terms of theory and method) employed by them, makes it difficult to draw concrete conclusions regarding whether the disambiguated and antireductionist aspect of interdisciplinarity is shared by the majority of LUCID researchers.

The results of surveys and interviews indicate this disparity may be linked with what Sayer (2000) calls "disciplinary parochialism" and "its close relative disciplinary imperialism" wherein thinking outside the framework of a single discipline is inhibited (Sayer 2000:7). As he argues, this parochialism and imperialism is hard for disciplinarians to see, because they seek theoretical explanations that seem to enlarge the claims of the disciplinary thinking with which they are familiar (Sayer 2000). This could be "a recipe for reductionism, blinkered interpretation and misattributions of causality" (Sayer 2000:7). Based on this, although the risk of falling into reductionism seems to be higher in the research conducted in disciplinary departments, we could, however, identify some of the LUCID examples that were conducted in interdisciplinary centers and shared the reductionist tendencies.

In explaining this, we suggest that a lack of reflexivity and selfcriticism of philosophy of science used by the researcher may play a major role in the tendency of reductionism in research. According to Bhaskar et al. (2017), reflexivity, the capacity of a researcher to monitor and account for her activity, can be potentially enhanced by giving a better explanation (theory) of what is it that we do (practice). Expanding our knowledge about other theories and practices, however, requires some familiarity with other disciplines, at least one or two beyond one's home discipline (Bhaskar et al. 2010). In the absence of learning and practicing new ways of thinking about a given problem, the process of reflexivity in research is more difficult to achieve given the lack of a useful point of reference for self-criticism.

Integration of knowledge for explanations of a laminated totality Another feature of interdisciplinary research highlighted by CR is explaining a laminated system containing emerging mechanisms and relations of dependence at the level of material exchange with nature, of social structure, of social interactions between people, and the level of the person. Achieving such explanations requires familiarity with the logic of retroduction, or simply the logic of theory building where "we develop theory that outlines the circumstances that must have existed to result in the situation that we are trying to explain" (Bhaskar et al. 2017:235). Through the process of retroduction, researchers move beyond empirical and actual domains to construct hypotheses or explanations of generative mechanisms that would account for the subject of their studies.
Many of the ideas and explanations of the given sustainability challenges in the evaluated LUCID research were inspired by political ecology theories and methods. For example, 12 out of $17 \mathrm{PhD}$ graduates and several senior researchers used political ecology as their research framework to bring together social and natural explanations of different complex, open-systems phenomena including climate change (Bettini 2013, Kaijser 2014, Kaijser and Kronsell 2014, Malm 2014, Carton 2016, Hornborg 2016, Warlenius 2017), water issues (Islar 2013, Nastar 2014, Ramasar 2014), biodiversity loss (Krause 2013), and land use change (Andersson 2014, Hansen 2014, Sjöström 2015, Valencia 2016).

The process of development of theories was, however, not limited to this work, and in many cases it is possible to trace the retroductive process in LUCID research where researchers incorporated different theories, analogies, and concepts to explain a phenomenon beyond their empirical cases. In the process of retroduction, researchers begin with a theory that they believe is at least initially appropriate for explaining a phenomenon. As the research process develops, however, researchers realize some aspect of the object of study has been left out of their initial conceptualization, as when there is inconsistency and contradiction in the logic of explanation or anomalies in the empirical data. This then requires that researchers seek to develop new theoretical insights to be able to address these contradictions or anomalies. This process in some of the LUCID research is elaborated in relation to the logic of dialectic (Hansen 2014, Malm 2014, Ramasar 2014, Sjöström 2015, Carton 2016, Warlenius 2017, Boda 2018).

Although one could argue that the retroductive approach, in comparison with inductive or deductive approaches, is dominant in LUCID, we should note that this does not guarantee an interdisciplinary research outcome. As Bhaskar et al. (2010) argue, in order to get a grasp on the deep structures and mechanisms that constitute the explanatory objects of scientific knowledge, the researcher needs to be at least familiar with a second, or even third, discipline as a strong point of reference. It is only then that the researcher can explore different explanations of a common phenomenon and get familiar with the process of retroduction, which can then be employed to investigate deep structural tendencies in the world. In the absence of such multidisciplinary conditions, the assumed interdisciplinary research may revert to "mono-disciplinary dogmatism" (Bhaskar et al. 2010:20).

\section{Methodological pluralism}

Conducting interdisciplinary research, from CR perspective, also requires methodological pluralism. In Bhaskar et al.'s (2010) view, methodological pluralism should go beyond a simple pooling of the knowledge from different disciplines. Rather, it requires synthetic integration of the knowledge, including integration of theories as well as methods from various disciplinary traditions in explaining and addressing multiple causes of complex events.

Assessing to what degree methodological pluralism, in terms of integration of theories from different disciplines, has been achieved in LUCID is, however, not straight forward. This is because of a variety of reasons: First, many concepts and theories may be employed in several disciplines, meaning that positioning these theories in one discipline or another is a matter up for debate. 
Second, there exists research where different theories are used and integrated, but these theories are not necessarily sourced from different disciplines. Third, the research that does employ different theories from multiple disciplines may not necessarily succeed in a meaningful synthetic integration of knowledge to explain different aspects of the problem. Thus, it is very difficult to evaluate how methodological pluralism at the theoretical level has been achieved to pursue interdisciplinarity. Nevertheless, if we look at all the research in each LUCID thematic category, we can argue such synthetic integration of knowledge has been achieved in LUCID, as we discussed above and in relation to the water scarcity research theme.

As for the methods of data collection and analysis, a relatively more straight forward research aspect to evaluate, 12 (out of 29) researchers combined different qualitative methods (Bettini 2013, Islar 2013, Jerneck and Olsson 2013, Hansen 2014, Kaijser 2014, Nastar 2014, Ramasar 2014, Magnusdottir and Kronsell 2015, Sjöström 2015, Carton 2016, Valencia 2016), while other researchers opted to employ a mixed-methods approach including both qualitative and quantitative methods (Krause 2013, Yengoh 2013, Andersson 2014, Malm 2014, Busch 2016, Warlenius 2017, Boda 2018; E. Johansson, unpublished manuscript). Although qualitative methods were largely linked with critical thinking tradition, a mixed-methods approach was associated both with critical thinking and problem-solving research strategies. Only in a couple of cases, researchers exclusively used quantitative methods while employing a problem-solving approach to the analysis of their data, e.g., by the use of databases of land information and simulation programs to visualize the connectivity of the global land acquisition system (Seaquist et al. 2014, Johansson et al. 2016).

As can be seen above, the majority of research strategies employed by the LUCID researchers share some features of the methodological pluralism approach, mainly in terms of using and integrating different methods from different disciplines. As noted by Thorén (2015), transfer of methods from different disciplines to investigate causes of certain phenomena can result in methodological pluralism. However, this is not always sufficient for interdisciplinarity. To establish fruitful interdisciplinary research a methodological pluralism is needed wherein several disciplines contribute particular theories, methods, and/or questions to address problems (Olsson et al. 2015).

As a final note here, it is important to point out that although researchers could associate their work with either or both research strategies, i.e., critical thinking vs. problem-solving, a few LUCID researchers have questioned the implications of this very distinction, arguing these categories should not be viewed as mutually exclusive, or that other distinctions, such as normative vs. descriptive, or interpretivist vs. positivist, could have been used instead (e.g., see Bettini 2013, Brandstedt 2013, Islar 2013, Carton 2016).

The recognition of these two modes of scientific inquiry, as described by Robert Cox in his seminal paper from 1981 (Cox 1981) was a hallmark of our approach to sustainability science from the outset of LUCID (Jerneck et al. 2011). Insights through the interdisciplinary collaboration gradually changed the view of critical and problem solving research from mutually exclusive (Cox's view) to mutually reinforcing, a position supported by a critical realism approach (Mahmoud, Jerneck, Kronsell, and Steen, unpublished manuscript).

\section{Institutional settings}

Administrative and financial arrangements

In the surveys and interviews conducted with LUCID participants, each researcher was asked to reflect on the role of their home institutions in terms of encouraging or constraining their engagement in LUCID. Except in a couple of cases, the researchers indicated that there were no formal constrains given that LUCID funded (fully or partially) $\mathrm{PhD}$ positions and $20 \%$ of seniors' full time positions. In addition, LUCID provided office spaces at LUCSUS where all the PhD candidates had the option of sitting and working together. While some took this opportunity and spent most of their research time at LUCSUS, others who were affiliated with other departments/centers found it difficult to have two office bases. As such, they argued that their home institutional responsibilities, e.g., teaching, participating in seminars, meetings, etc., made it difficult to sit and work at LUCSUS. The senior researchers also echoed the issue of time management that sometimes prevented them from more active participation in the LUCID program. For example, one of the interviewees mentioned the following:

\section{I have had a number of assignments on different positions since we started LUCID... which have taken a lot of time... with having other research projects, in a way there has been too little time throughout the program for me to participate as much as I would have liked to... It is a pity but I think it has happened to almost all of us... Now I'm in a position that I have not been able to spend my $20 \%$ [allocated LUCID budget] for a long time... (Interviewee \#1)}

Other senior researchers also stated similar issues where they could not use the LUCID fund because of their commitment to other projects in their home institutions. The resulting lack of senior research engagement, in turn, led to some frustration among LUCID PhD candidates and graduates as reflected in the following statements:

My major critique of the LUCID program is the lack of engagement from seniors, which made achieving the LUCID objectives difficult for LUCID PhDs. You can't expect that young aspiring researchers can integrate natural and social theories and methods, this is something that needs to be guided and this was missing. That doesn't mean that the PhDs didn't do interdisciplinary research, but the ambitions and achievements could have been higher with actual involvement from senior researchers. (From survey \#2)

$\ldots[A] s$ an inexperienced researcher, it's really challenging to navigate the entirety of theories and methods that potentially could be relevant/important for your research. You always feel like you might be missing something fundamental and that someone at any point might come at you with critiquelquestion from an entirely different angle than you are working from. This is inevitable though I think. I definitely think that more engagement from seniors would have helped, because we do have such a range of perspectives/traditions within 
Fig. 3. Process of interdisciplinarity in relation to water research in LUCID. Adopted from (Bhaskar et al. 2017, reproduced by permission of Tayor \& Francis Books UK)).

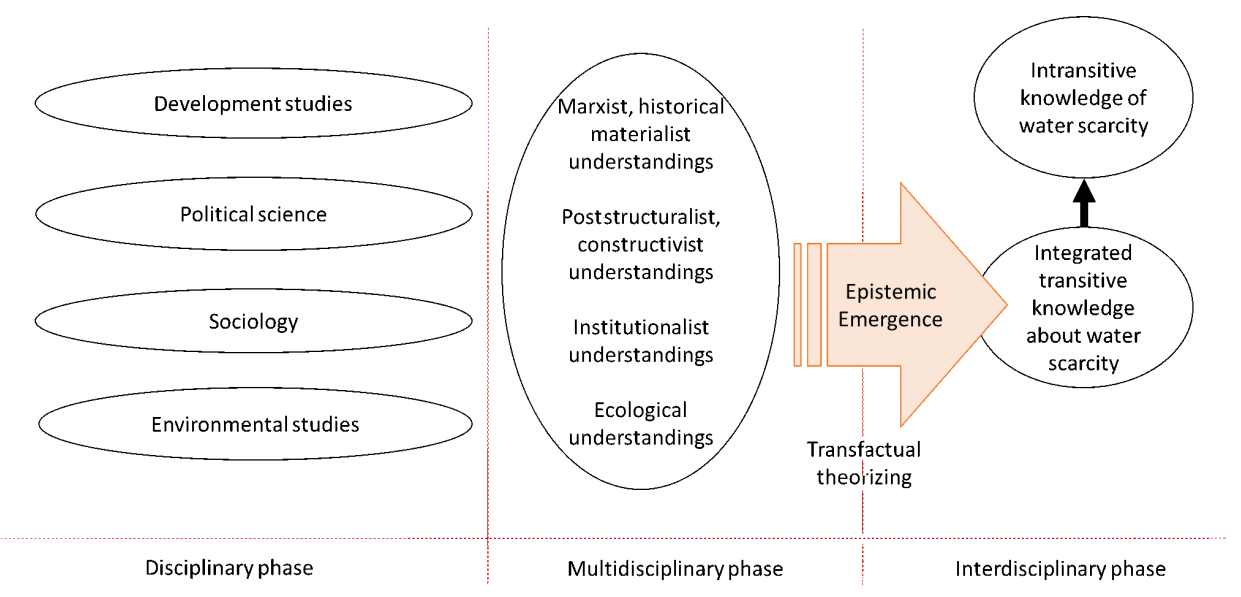

LUCID but I feel like very few of the steering committee members have an idea of what I and many others are doing, and I'm sure their input would have been very valuable. (From survey \#3)

Despite the above barriers to more effective collaboration between junior and senior researchers, there was a common consensus among researchers that the financial and administrative opportunities provided by LUCID have been helpful in supporting their conducting interdisciplinary research:

\section{... I think LUCID has been pretty unique in creating space for and enabling dialogue across a number of fields/ approaches. I do not think there are many centers like LUCID in Europe, in particular not many as pluralistic as LUCID. Looking at the LUCID experience from another country, I think this added great value for and should be regarded as great success for the involved departments, for Lund University, and more broadly for the Swedish academic system. (From survey \#4)}

In particular, many $\mathrm{PhD}$ candidates and graduates stated that having supervisors from different disciplines/fields was valuable in exploring sustainability challenges from different perspectives. Although the financial arrangements and provisioning of working space in LUCID created opportunities for interdepartmental supervision and research, the influence of formal departmental settings, in which many researchers remained anchored, in some ways constrained the potential for more proactive and effective collaboration in LUCID.

\section{Familiarity with other disciplines}

The majority of the PhD graduates (12 out of 17) who entered into the LUCID program were either graduates of an interdisciplinary MSc program or had been exposed to interdisciplinary research to some extent previously. In addition to this background foundation, which many LUCID researchers possessed, the organization of regular weekly seminars; midterm, final, and defense seminars of PhDs; as well as yearly LUCID workshops, provided good avenues for researchers to get familiar with other disciplines and explore new perspectives on common research themes. Despite these opportunities, however, one aspect that was mentioned by several researchers as needing to be strengthened was insufficient dialogue between social and natural scientists.

My initial ambition was to have a stronger natural science
component, or at least take some natural science oriented
courses. But engagement from natural scientists in the
LUCID program was lacking/insufficient and no such
courses were offered (and their own courses are not
adapted to social scientists). (From survey \#5)
Interdisciplinary research is challenging in the sense that
my knowledge of natural sciences isn't as strong as it
should be. (From survey \#6)
... The fact that the program did not include more than 1
natural science institution somehow put a limit on how
interdisciplinary the program as a whole was. (From
survey \#7)

Although this had been formally discussed at LUCID steering committee meetings on various occasions, it was not an easy issue to address. One issue, as noted by Cornell (2010), may be that many natural scientists are not equipped for critical reflection on the knowledge creation or transformation process when entering into interdisciplinary areas of research. As a result, the process of finding and collaborating with natural science based departments and researchers who are willing and enthusiastic to engage with social science topics and subjects becomes challenging.

Having a sense of a secure, recognized place or home

Although formal obligations related to an individual researcher's home department may have impacted their ability to engage in interdisciplinary work at LUCID, having one foot in a home department is not in itself a bad thing. Indeed, Bhaskar et al. (2010) suggests that one of the keys to successful interdisciplinary research is having a sense of security in one's home institution, both now and in the future. Although LUCSUS as the coordinating node of the LUCID program was deemed to be supportive in giving this sense of security by the researchers 
interviewed and surveyed, the regulations and structure at other disciplinary departments may have been less conducive to creating such a sense of security. For example, one of the interviewees stated the following:

In order to do that [to be promoted in your current institution], you need to pay attention to disciplinary regulations and structures... It would have been easier to have come on board as an older person, already having jumped through all of those hoops and feeling free to be able to do whatever... LUCID has helped in some ways most definitely, but it has also hindered in other ways... I will not be promoted in sustainability science... I need to show the people who evaluate things here that I can do [X discipline]... perhaps without having to be worried about prizing for the academic ranks, some people don't care about that, but I do, I like to have the sense of accomplishment behind me... (Interviewee \#8)

$\mathrm{PhD}$ candidates and graduates echoed similar concerns about the unknown future after being trained and engaged in an interdisciplinary program like LUCID. To address this issue, LUCID provided short-term research funding opportunities (up to three months) for $\mathrm{PhD}$ graduates while looking for jobs in and outside academia. This proved to be a significant mechanism to support the research outreach in different geographical case studies, to expand the social and career networks, and more importantly to bring $\mathrm{PhD}$ graduates and senior researchers together in writing joint research proposals, increasing the opportunity of conducting interdisciplinary research in the future.

\section{THE FUTURE OF INTERDISCIPLINARY RESEARCH AND LUCID}

\section{Emergence of interdisciplinarity}

As postulated by a CR perspective, an integrated interdisciplinary understanding of phenomena like climate change, land use change, water scarcity, and biodiversity loss can be achieved by epistemic emergence and transfactual theorizing (Fig. 2). But how does such a process of epistemic emergence, based on theorizing about the structures and mechanisms at the different level of reality, actually look in practice? In other words, how do researchers working on complex open-systems phenomena achieve an interdisciplinary understanding? Here, the LUCID examples can offer important insights. In particular, we draw on the water scarcity issue as a more concrete case of open-systemic phenomenon to take a deeper look at the process of interdisciplinary research in LUCID, as shown in Figure 3.

From the start, the researchers working on the water research theme based their work on past-acquired, largely disciplinary knowledge. These included perspectives from development studies, political science, sociology, and environmental studies. During the multidisciplinary phase of knowledge development, these water researchers started to pick up new analogies, metaphors, and models to construct an explanation that fits the new kind of reality in relation to their case studies. This resulted in the problem of water scarcity being reframed in terms of issues of well-being and vulnerability in peri-urban areas around Bogotá, Colombia (Valencia 2016), inequality in access to water services in Hyderabad, India and Johannesburg, South Africa
(Nastar 2014), politics of scaling in allocation and distribution of water resources in South Africa (Ramasar 2014), and water rights controversies in Turkey (Islar 2013). These new ideas, on the one hand, were inspired by the fieldwork, literature review, document analysis, interviews, and in general data collected regarding the case studies. On the other hand, they were stimulated through interprofessional cooperation, wherein researchers strived to understand and employ concepts from disciplines and fields other than their own. Within the team, the ability to communicate effectively these cross-disciplinary understandings of water issues at different platforms, e.g., through coordination of courses, joint workshops and seminars, attending a relevant conference theme collectively, coauthorship of journal papers, and so forth, was essential to create new ideas about multiplicity of mechanisms leading to the issues of water scarcity. The new ideas that emerged at this stage were influenced by various perspectives, broadly categorized as Marxist/historical materialist, poststructuralist, institutionalist, and ecological understandings.

In seeking for transfactual explanation for the various issues of water scarcity being studied, LUCID water researchers had the opportunity to compare their theoretical understandings against competing theories that they had become familiar with during the multidisciplinary research phase. Although explanations differ from one case to another, we could highlight common dominators for explaining a multiplicity of causes and mechanisms leading to what is framed as water scarcity. These include, for example, geohistorical elements, e.g., postcolonial Colombia, postapartheid South Africa, or postindependence India; ill-regulated property rights systems in allocation and access to land and water; impacts of market-based discourses and narratives in rural and urban development plans and the interactions of different groups whose livelihoods depend on having access to water.

In conducting interdisciplinarity, it might not be possible to get a perfectly integrated picture without any distortions, gaps, or inconsistencies. Instead, the interdisciplinary knowledge that has emerged through the LUCID process involves a constellation of complementary but irreducible and often unintegratable conceptual contributions. In these outcomes, the limits of some disciplinary contributions become more apparent, which then provides further opportunity to identify in what ways these limited perspectives can be supported by bringing in other disciplinary perspectives. In the final analysis, from a CR perspective, the idea should always be to develop the conceptualization of a problem, such as water scarcity, toward more comprehensive and inclusive totalities rather than breaking a complex problem down into its individual constituent parts. To this end, the LUCID water example brought to the fore the political economy and ecology aspects of water in different cases studies beyond the issue of scarcity.

\section{Research centers: the impacts on and challenges for interdisciplinarity}

Our findings from conducting research at LUCID indicate that interdisciplinary centers like the center for sustainability studies and departments of human geography and human ecology provide a more supportive environment for interdisciplinarity than mono-disciplinary departments such as political science, philosophy and physical geography. This is both in terms of cross- 
pollination of theories and methods, but also in terms of education of $\mathrm{PhD}$ students and their supervision.

Considering the above, we argue that disciplines with a strong disciplinary identity would have more difficulties in embracing the interdisciplinary research in LUCID. Interdisciplinarity, as pointed out by several research studies, can be seen as a reaction against disciplines and is paradoxically both praised and thwarted by academia. For instance, in exploring the drivers of scholars working within disciplines, Blackmore and Kandiko (2011) liken academia to a "prestige economy," a term used by anthropologists to describe "goods through which social approval and social status are gained" (Bascom 1948:211). Publications, citations, and research grants are some of these goods by which scholars attain social approval and status. But status is not only associated with individuals working within disciplines; different disciplines are also associated with different degrees of status and power (Biglan 1973, Becher and Trowler 2001). Following this, Moran (2006) argues that disciplines are fields of power and control of the organization of knowledge, and Hicks et al. (2010) contend even if the interdisciplinarity may have higher impact than disciplinary research, it is controversial because it challenges the established order. For example, interdisciplinarity was considered a threat to the discipline of sociology in times of increasing use of research audits (Holmwood 2010). He argued that sociology as a discipline was threatened by various forms of applied social sciences characterized by Mode 2 Knowledge (Gibbons et al. 1994), which is ostensibly a preferred mode of research by most nonacademic interest groups and funders (Holmwood 2010). These factors led to various obligations and concerns over the future for those researchers who were formally placed at a mono-disciplinary department. As a result, on many occasions, they were constrained in their abilities to take full advantage of the LUCID interdisciplinary institutional settings.

The interdisciplinary centers in LUCID, on the other hand, provided a context within which a variety of disciplines and a plurality of methodological approaches were more readily sourced. In this sense, it seems apparent that horizontal integration within universities could help facilitate the process of cross-disciplinarity (multidisciplinary phase; see Fig. 2) wherein researchers can employ a variety of concepts across disciplines and fields other than their own. LUCID, as a research center, took a further step in going beyond the multidisciplinary phase, by providing supportive financial and administrative arrangements as well as an intellectual environment needed for interdisciplinarity. As we could see in LUCID examples, having access to experts in a variety of fields helps facilitate interdisciplinary research in many cases.

Having mentioned the importance of horizontal integration, we should, however, note that the existence of such interdisciplinary centers depends on universities' support at a higher level, both in terms of finance and recognizing the value of interdisciplinary research. In this sense, the role of vertical integration becomes crucial.

The LUCID research school was funded by a Linnaeus grant, which was an experiment by two Swedish research councils during a limited period to provide long-term (10 years) substantial (about US\$1 million per year) grants to research groups or consortia of international standing. The funding agencies were explicit in their ambition to contribute to a structural change of universities, often in the direction of increasing interdisciplinarity. This was obviously highly controversial among many disciplinary scholars and university leaders. If the higher-ups in universities, at the faculty level or above, do not support institutional arrangements conducive to interdisciplinary research, then the options of providing such supportive institutional settings are extremely limited, or even (financially and institutionally) impossible. The current trend, at least in Sweden, seems to be in this direction: several universities seem to strengthen the power of faculties at the disadvantage of interdisciplinarity across faculty lines.

\section{CONCLUSIONS}

Evaluating LUCID research activities over the last decade provides important insights into how authentic social-natural science integration can best be accomplished. By applying a set of criteria grounded in critical realism, we found that LUCID research, which employed the logic of retroduction and the principles of methodological pluralism (in terms of both theory and method integration), is more likely to produce successful interdisciplinary research. By using the example of LUCID water research in particular, we demonstrated how a plurality of different social science perspectives can be incorporated to examine the underlying political economic drivers of water scarcity issues. The LUCID experience supports the viewpoint that engaging in interdisciplinary research endeavors does not necessarily mean one must give up their disciplinary knowledge and background (cf. Haider et al. 2018), a point similarly emphasized within critical realism (Bhaskar et al. 2017). To the contrary, during the interdisciplinary process, disciplinary insights are clarified and enhanced as the researcher becomes more aware of their limitations and recognizes the specific needs regarding bringing in new perspectives to better explain a complex open-system phenomenon.

Evaluating institutional settings at LUCID provided us with insights into the role of research centers and departments in facilitating the process of producing successful interdisciplinary research, which we found to be in many ways limited in the monodisciplinary departments. These limitations were related in particular to individual researchers being burdened with a variety of obligations in their home department that restricted their ability to participate in interdisciplinary research activities. Concerns over prospects for career opportunities also restricted the participation of some researchers. We suggest these constraints might be related to the more restricted educational content and character of mono-disciplinary departments in terms of controlling the organization of knowledge. Interdisciplinary research centers affiliated with LUCID, on the other hand, tended to provide a more supportive institutional and intellectual environment, specifically in terms of cross-pollination of theories and methods, as well as flexibility in multidisciplinary education of $\mathrm{PhD}$ students and their supervision. Our analysis supports the claim that providing a conducive institutional environment can help facilitate the production of interdisciplinary research. The LUCID examples also suggest that these benefits are especially strongly felt at the $\mathrm{PhD}$ level.

In addition to the role of formal institutional arrangements in making the process of interdisciplinarity even more fruitful, we want to highlight the importance of channels of collaborations 
between $\mathrm{PhD}$ candidates and senior researchers. In addition to supervision processes, the joint LUCID workshops and seminars, writing thematic papers for journal special issues or book publications, or writing joint research proposals help support a more productive environment for the $\mathrm{PhD}$ candidates in engaging with interdisciplinarity. As LUCID experience shows, this, on the one hand, depends on effectively tackling coordination issues. On the other hand, it depends on the availability, support, and willingness of senior researchers in leading collective research initiatives with involvement of PhDs. As pointed out by the LUCID PhD candidates and graduates surveyed in this study, in the absence of effective channels of communication with senior researchers, the expectations of being pioneers in conducting interdisciplinary research might not be met, or at least may be diminished.

Facilitating interdisciplinarity in research, as demonstrated in this article, is a process; it does not just happen, but must be pursued and progressively improved, and this requires consistent funding and other institutional support as much as it requires researchers willing to step outside of their disciplinary comfort zones. Our modest hope is that others interested in furthering this necessary shift toward interdisciplinarity can learn from LUCID's largely effective and innovative institutional organization and its thematic research focus, as well as from its shortcomings.

${ }^{[1]}$ If we look at two of the most prestigious prizes since 1990, e.g., the Blue Planet Prize and the Volvo Environment Prize, for the research on global sustainability issues, only $2 \%$ of the 100 awarded laureates are social scientists. See Appendix 1.

Responses to this article can be read online at: http://www.ecologyandsociety.org/issues/responses. php/10218

\section{Acknowledgments:}

We thank the Swedish research council Formas (contract number: 259-2008-1718) funding the Linneaus Center LUCID at Lund University. We appreciate our LUCID colleagues' comments on the very first draft of the paper presented in the LUCID seminar as well as their participation in the survey and interviews. We would also like to thank Dr. Turaj Faran for the rich and insightful dialogues on critical realism and philosophy of science which helped us to develop the theoretical framework of the paper.

\section{LITERATURE CITED}

Andersson, E. 2014. Fertile grounds? Collective strategies and the political ecology of soil management in Uganda. Dissertation. Lund University, Lund, Sweden. [online] URL: http://portal.research. lu.se/portal/files/6194597/4437977.pdf

Archer, M. S., and R. Bhaskar. 1998. Critical realism: essential readings. Routledge, London, $\mathrm{UK}$.

Bascom, W. R. 1948. Ponapean prestige economy. Southwestern Journal of Anthropology 4:211-221. http://dx.doi.org/10.1086/ soutjanth.4.2.3628712
Becher, T., and P. Trowler. 2001. Academic tribes and territories: intellectual enquiry and the culture of disciplines. Open University Press, Buckingham, UK.

Bettini, G. 2013. Climatised moves-climate-induced migration and the politics of environmental discourse. Dissertation. Lund University, Lund, Sweden. [online] URL: http://lup.lub.lu.se/ search/ws/files/5816069/3736730.pdf

Bhaskar, R. 2009. Scientific realism and human emancipation. Routledge, London, UK.

Bhaskar, R. 2013. A realist theory of science. Routledge, London, UK.

Bhaskar, R., B. Danermark, and L. Price. 2017. Interdisciplinarity and wellbeing: a critical realist general theory of interdisciplinarity. Taylor \& Francis, London, UK.

Bhaskar, R., C. Frank, K. G. Høyer, P. Næss, and J. Parker, editors. 2010. Interdisciplinarity and climate change: transforming knowledge and practice for our global future. Routledge, London, UK.

Biglan, A. 1973. The characteristics of subject matter in different academic areas. Journal of Applied Psychology 57:195-203. http:// dx.doi.org/10.1037/h0034701

Blackmore, P., and C. B. Kandiko. 2011. Motivation in academic life: a prestige economy. Research in Post-Compulsory Education 16:399-411. http://dx.doi.org/10.1080/13596748.2011.626971

Boda, C. 2018. The beach beneath the road: sustainable coastal development beyond governance and economics. Dissertation. Lund University, Lund, Sweden. [online] URL: http://lup.lub.lu. se/search/ws/files/36216939/E_nailing_Chad.pdf

Brandstedt, E. 2013. The construction of a sustainable development in times of climate change. Dissertation. Lund University, Lund, Sweden. [online] URL: https://philarchive.org/archive/BRATCO-47

Busch, H. 2016. Entangled cities: transnational municipal climate networks and urban governance. Dissertation. Lund University, Lund, Sweden. [online] URL: http://lup.lub.lu.se/search/ws/ files/13139045/e nailing_Henner.pdf

Carton, W. 2016. Fictitious carbon, fictitious change?: Environmental implications of the commodification of carbon. Dissertation. Lund University, Lund, Sweden. [online] URL: http://lup.lub.lu.se/search/ws/files/11379396/Wim Carton thesis. pdf

Cornell, S. 2010. Climate change: brokering interdisciplinarity across the physical and social sciences. Pages 116-134 in R. Bhaskar, C. Frank, K. G. Høyer, P. Næss, and J. Parker, editors. Interdisciplinarity and climate change: transforming knowledge and practice for our global future. Routledge, London, UK.

Cornell, S., F. Berkhout, W. Tuinstra, J. D. Tàbara, J. Jäger, I. Chabay, B. de Wit, R. Langlais, D. Mills, P. Moll, et al. 2013. Opening up knowledge systems for better responses to global environmental change. Environmental Science \& Policy 28:60-70. http://dx.doi.org/10.1016/j.envsci.2012.11.008

Cox, R. W. 1981. Social forces, states and world orders: beyond international relations theory. Millennium: Journal of International Studies 10:126-155. http://dx.doi.org/10.1177/0305$\underline{8298810100020501}$ 
Creaven, S. 2012. Marxism and realism: a materialistic application of realism in the social sciences. Taylor \& Francis, London, UK.

Gibbons, M., C. Limoges, H. Nowotny, S. Schwartzman, P. Scott, and M. Trow. 1994. Thenew production of knowledge: the dynamics of science and research in contemporary societies. Sage, London, UK.

Haider, L. J., J. Hentati-Sundberg, M. Giusti, J. Goodness, M. Hamann, V. A. Masterson, M. Meacham, A. Merrie, D. Ospina, C. Schill, and H. Sinare. 2018. The undisciplinary journey: earlycareer perspectives in sustainability science. Sustainability Science 13:191-204. http://dx.doi.org/10.1007/s11625-017-0445-1

Hansen, M. 2014. Struggles over conservation space: social justice in the iSimangaliso Wetland Park, South Africa. Dissertation. Lund University, Lund, Sweden. [online] URL: http://lup.lub.lu. se/search/ws/files/5774105/4285041.pdf

Hicks, C. C., C. Fitzsimmons, and N. V. C. Polunin. 2010. Interdisciplinarity in the environmental sciences: barriers and frontiers. Environmental Conservation 37:464-477. http://dx.doi. org/10.1017/S0376892910000822

Holmwood, J. 2010. Sociology's misfortune: disciplines, interdisciplinarity and the impact of audit culture. British Journal of Sociology 61:639-658. http://dx.doi.org/10.1111/j.1468-4446.2010.01332. $\underline{\mathrm{X}}$

Hornborg, A. 2016. Global magic: technologies of appropriation from ancient Rome to Wall Street. Palgrave Macmillan, Basingstoke, UK. http://dx.doi.org/10.1057/9781137567871

Isaksen, K. R. 2016. Reclaiming rational theory choice as central: a critique of methodological applications of critical realism. Journal of Critical Realism 15:245-262. http://dx.doi. org/10.1080/14767430.2016.1169369

Islar, M. 2013. Private rivers: politics of renewable energy and the rise of water struggles in Turkey. Dissertation. Lund University, Lund, Sweden. [online] URL: https://lup.lub.lu.se/search/ publication/3735486

Jerneck, A., and L. Olsson. 2013. More than trees! Understanding the agroforestry adoption gap in subsistence agriculture: insights from narrative walks in Kenya. Journal of Rural Studies 32:114-125. http://dx.doi.org/10.1016/j.jrurstud.2013.04.004

Jerneck, A., L. Olsson, B. Ness, S. Anderberg, M. Baier, E. Clark, T. Hickler, A. Hornborg, A. Kronsell, E. Lövbrand, and J. Persson. 2011. Structuring sustainability science. Sustainability Science 6:69-82. http://dx. doi.org/10.1007/s11625-010-0117-x

Johansson, E. L., M. Fader, J. W. Seaquist, and K. A. Nicholas. 2016. Green and blue water demand from large-scale land acquisitions in Africa. Proceedings of the National Academy of Sciences 113:11471-11476. http://dx.doi.org/10.1073/pnas.1524741113

Kaijser, A. 2014. Who is marching for Pachamama? An intersectional analysis of environmental struggles in Bolivia under the government of Evo Morales. Dissertation. Lund University, Lund, Sweden. [online] URL: http://lup.lub.lu.se/search/ws/ files/6354466/4393812.pdf

Kaijser, A., and A. Kronsell. 2014. Climate change through the lens of intersectionality. Environmental Politics 23:417-433. http:// dx.doi.org/10.1080/09644016.2013.835203
Krause, T. 2013. Buying conservation-financial incentives for tropical forest conservation in the Ecuadorian Amazon. Dissertation. Lund University, Lund, Sweden. [online] URL: https://lup.lub.lu.se/search/publication/4057968

LUCID Science Plan. 2008. Lund University centre of excellence for integration of social and natural dimensions of sustainability. Lund University, Lund, Sweden.

Magnusdottir, G. L., and A. Kronsell. 2015. The (in)visibility of gender in Scandinavian climate policy-making. International Feminist Journal of Politics 17:308-326. http://dx.doi. org/10.1080/14616742.2014.896661

Malm, A. 2014. Fossil capital: the rise of steam-power in the British cotton industry, c. 1825-1848, and the roots of global warming. Dissertation. Lund Univeristy, Lund, Sweden. [online] URL: https://lup.lub.lu.se/search/publication/4250823

Moran, M. 2006. Interdisciplinarity and political science. Politics 26:73-83. http://dx.doi.org/10.1111/j.1467-9256.2006.00253.x

Nastar, M. 2014. Navigating troubled waters. An analysis of how urban water regimes in the global South reproduce inequality. Dissertation. Lund University, Lund, Sweden. [online] URL: http://lup.lub.lu.se/search/ws/files/5833135/4379516.pdf

O'Byrne, D., E. Isgren, and C. S. Boda. 2018. A reply to Balmford et al. (2017). Biological Conservation 218:293-294. http://dx.doi. org/10.1016/j.biocon.2017.11.004

Olsson, L., A. Jerneck, H. Thoren, J. Persson, and D. O'Byrne. 2015. Why resilience is unappealing to social science: theoretical and empirical investigations of the scientific use of resilience. Science Advances 1:e1400217. http://dx.doi.org/10.1126/sciadv.1400217

Ramasar, V. 2014. Fluid governance: scalar politics in the South African waterscape. Dissertation. Lund University, Lund, Sweden. [online] URL: http://lup.lub.lu.se/search/ws/

files/5983883/4791054.pdf

Sayer, A. 2000. Realism and social science. Sage, London, UK. http://dx.doi.org/10.4135/9781446218730

Schellnhuber, H. J. 1999. 'Earth system' analysis and the second Copernican revolution. Nature 402:C19-C23. http://dx.doi. org/10.1038/35011515

Seaquist, J. W., E. L. Johansson, and K. A. Nicholas. 2014. Architecture of the global land acquisition system: applying the tools of network science to identify key vulnerabilities. Environmental Research Letters 9:114006. http://dx.doi. org/10.1088/1748-9326/9/11/114006

Sjöström, C. 2015. Food for naught: the politics of food in agricultural modernization for African smallholder food security. Dissertation. Lund University, Lund, Sweden. [online] URL: http://lup.lub.lu.se/search/ws/files/6143744/5276893.pdf

Steffen, W., R. A. Sanderson, P. D. Tyson, J. Jäger, P. A. Matson, B. Moore, F. Oldfield, K. Richardson, H. J. Schellnhuber, and B. L. Turner II, R. J. Wasson. 2006. Global change and the Earth system: a planet under pressure. Springer, Berlin, Germany.

Thorén, H. 2015. The hammer and the nail: interdisciplinarity and problem solving in sustainability science. Dissertation. Lund University, Lund, Sweden. [online] URL: https://lup.lub.lu.se/ search/publication/5047237 
Valencia, S. 2016. Caught between spaces: socio-environmental vulnerability in formal and informal peri-urban Bogotá and Soacha, Colombia. Dissertation. Lund University, Lund, Sweden. [online] URL: http://portal.research.lu.se/ws/files/7631699/

Sandra Valencia FINAL for webb.pdf

Viseu, A. 2015. Integration of social science into research is crucial. Nature 525:291. http://dx.doi.org/10.1038/525291a

Warlenius, R. 2017. Asymmetries: conceptualizing environmental inequalities as ecological debt and ecologically unequal exchange. Dissertation. Lund University, Lund, Sweden. [online] URL: https:/lup.lub.lu.se/search/publication/ae43bfe9-7409-450e-8949$\underline{-8 \mathrm{e} 9 \mathrm{a} 478 \mathrm{~b} 53 \mathrm{~b} 8}$

Yengoh, T. G. 2013. Explaining agricultural yield gaps in Cameroon. Dissertation. Lund University, Lund, Sweden. [online] URL: https://lup.lub.lu.se/search/publication/3631523 


\section{Appendix 1}

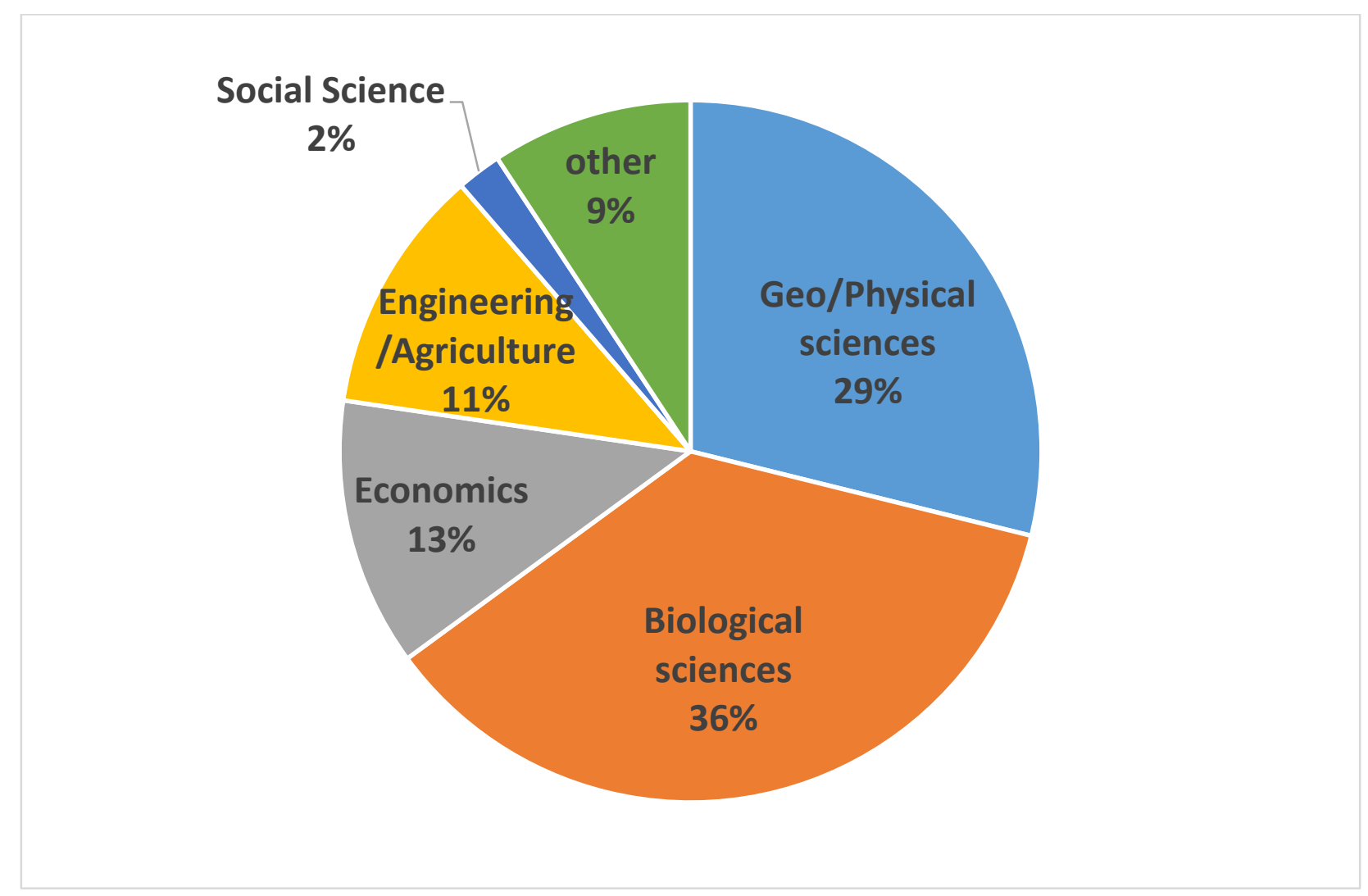

The figure shows the distribution of two of the most prestigious prizes, namely the Blue Planet Prize and the Volvo Environment Prize, based on laureates' disciplinary background, since 1990 to date.

Sources: http://www.af-info.or.jp/en/blueplanet/list.html and http://www.environment-prize.com/laureates/ 